\title{
Intraosseous suture technique with K-wire stabilisation for fixation of mallet fracture with DIPJ volar subluxation
}

\author{
M Solomons, ${ }^{2} \mathrm{~S}$ Isaacs ${ }^{2}$ \\ MBChB(UCT) FCS (Ortho), Professor, Consultant and Head of Unit, Martin Singer Hand Surgery Unit, Department of Orthopaedic Surgery, Groote Schuur \\ Hospital, Cape Town \\ 2 MBChB(UCT), Specialty Registrar: Dept. Of Plastic and Reconstructive Surgery, West Wing, John Radcliffe Hospital, Oxford University Hospitals NHS \\ Foundation Trust, Headley Way, Headington, Oxford
}

Corresponding author: Prof Michael Solomons, Consultant and Head of Unit, Martin Singer Hand Surgery Unit, Department of Orthopaedic Surgery, Groote Schuur Hospital, Observatory, Cape Town 8000, Email: docsol@absamail.co.za

\begin{abstract}
Background: Mallet fracture with distal interphalangeal joint (DIPJ) subluxation remains a challenging problem, with numerous techniques proposed for repair of this fracture.

Methods: The authors present a modified approach to mallet fractures with volar subluxed DIPJ by K-wire fixation and intraosseus suture of the avulsed extensor tendon.

Results: The described technique resulted in successful clinical management of 12 patients with isolated mallet fractures with volar subluxation with $1 / 12$ patients having a complication of stable non-union.

Conclusions: The intraosseous suture technique with K-wire stabilisation offers a simple and reproducible technique of fracture reduction and stabilisation of volar subluxed DIPJ mallet fractures.
\end{abstract}

Key words: mallet fractures, DIPJ volar subluxation, surgical technique, mallet injury, K-wire stabilisation

Citation: Solomons M, Isaacs S. Intra-osseous suture technique with K-wire stabilisation for fixation of mallet fracture with DIPJ volar subluxation. SAOJ 2017;16(3):70-73. DOI 10.17159/2309-8309/2017/v16n3a10

Editor: Prof Anton Schepers, University of the Witwatersrand

Received: August 2016 Accepted: December 2016 Published: August 2017

Copyright: (C) 2017 Solomons M, Isaacs S. This is an open-access article distributed under the terms of the Creative Commons Attribution Licence, which permits unrestricted use, distribution and reproduction in any medium, provided the original author and source are credited.

Funding: The authors have no sources of funding to declare.

Conflict of interest: The authors have no conflicts of interest to declare.

\section{Introduction}

The size of the fracture fragment, the percentage of joint surface involvement and the association with joint subluxation have all been offered as indications for operative intervention in mallet finger fracture. ${ }^{1-6}$

There still remains no clear consensus regarding the indications for operative intervention in the literature.

Once a decision to intervene surgically has been made, the surgeon is confronted with a litany of options. ${ }^{4,6-18}$ The commonly utilised surgical technique of extension blocking wire only serves to reduce the displaced fractures but struggles to contain the volar subluxation of the distal phalanx..$^{1,19-21}$

Furthermore, as these wires are passed percutaneously into the distal interphalangeal joint (DIPJ), the risk of intra-articular sepsis is not inconsequential.

Some surgeons prefer passing a small screw into the fragment but this carries the serious potential risk of splitting an already small bone fragment and substantially increasing the complexity of the surgery. ${ }^{22}$ 
Below, we present a modified approach which resulted in successful clinical management of isolated mallet fractures with volar subluxation in a series of patients.

\section{Indications/contraindications}

All patients presenting to our hand unit with a mallet fracture associated with volar subluxation were included in the study. We enrolled 12 patients with mallet finger injuries over an 18-month period. The average age of the patients was 29.2 years with an age range of 15 to 56 years. The average interval from injury to surgery was 26 days with a range of 5 to 49 days.

Ethics committee approval for this retrospective study was obtained. Informed consent was obtained from all patients and clinical notes and radiological material were reviewed.

Post-operative assessment included measurement of fixed flexion deformity, extensor lag and end range flexion.

\section{Surgical technique}

The surgical procedure is performed either under general anaesthetic or regional anaesthetic (Biers block).

The patient lies supine with the arm placed outstretched on a hand operating table. A bloodless field is created with the use of a tourniquet. A dorsal Y-shaped (Mercedes Benz) incision is utilised (Figure 1). Full thickness skin flaps are elevated with careful protection of the germinal matrix.

At this stage, care needs to be taken to elevate the fracture from distal to proximal. Clearly, it would be a gross surgical error to attempt to create a dissection plane between the fracture and the extensor tendon. The fracture is carefully elevated from the fracture bed and reflected proximally. The DIPJ, including the fractured terminal phalanx, can be seen in a volar subluxed position. Careful curettage of the fracture bed should remove most of the haematoma and/or early soft callus. Usually the terminal phalanx can be reduced from the volar subluxed position but in the case of a substantial delay, it might be necessary to perform a limited release of the collateral ligaments.

At this stage, the very small fragment is stabilised in an Adsons forceps. A 23-gauge needle is then chosen as a drilling device. The hub needs to be removed and the needle placed into a wire driver. Two holes are drilled parallel starting from the raw fracture surface and exiting on the dorsal base at the insertion of the extensor tendon (Figure 2).

Subsequently, two 23-gauge needles are inserted from dorsal to volar through the small fragment. They are passed through until the tips of the bevel are visible in the fracture site. It is important now to reduce the dislocation and to reduce the fracture as well as possible. Using a finger drilling technique on the 23-gauge needles, holes are drilled through the volar component of the terminal phalanx. This ensures that the sequential holes in the two separate fragments are continuous. If this were not the case, displacement is likely to occur as the suture is tightened.

Once the starter holes are made in the fracture bed of the terminal phalanx, then the fracture fragment can be removed and the rest of the procedure performed by passing needles freehand through the terminal phalanx using the starter holes as a positioning guide. The two needles are passed through the volar cortex and delivered into a second separate longitudinal volar incision at the base of the terminal pulp. It is important to get the dissection all the way down to the flexor insertion at the level of the periosteum. It is mandatory that no soft tissue gets trapped by the suture material (Figure 3).

A prolene suture is pretensioned and the needle is removed. The two ends are passed through the bevels of the 23-gauge needles to exit dorsally through the fracture site. The needles are removed and the two ends are pulled so that the sutures lie snug against the volar periosteum, with no evidence of any soft tissue impingement and most importantly no neurovascular compromise (Figure 4).

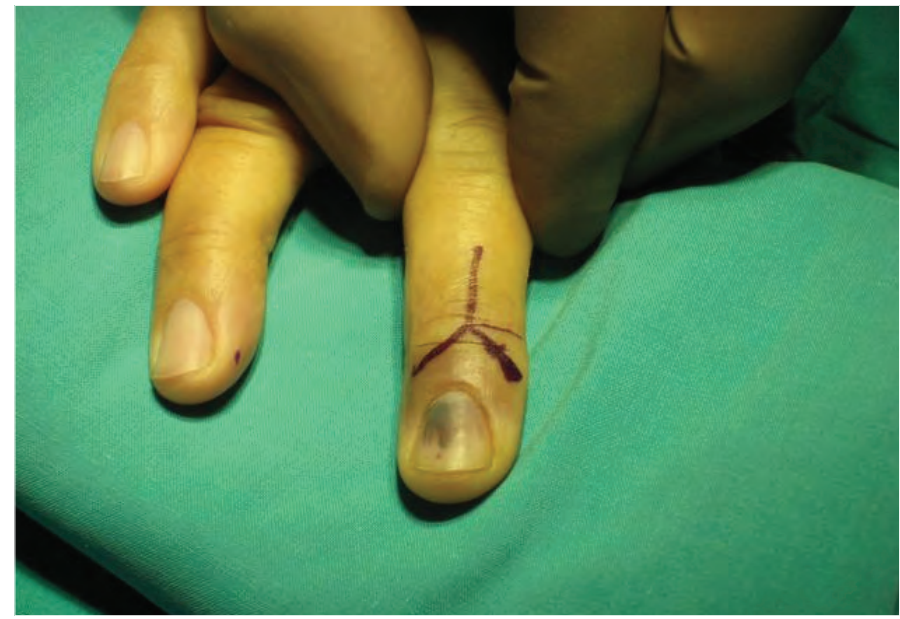

Figure 1. Dorsal Y-shaped (Mercedes Benz) incision.

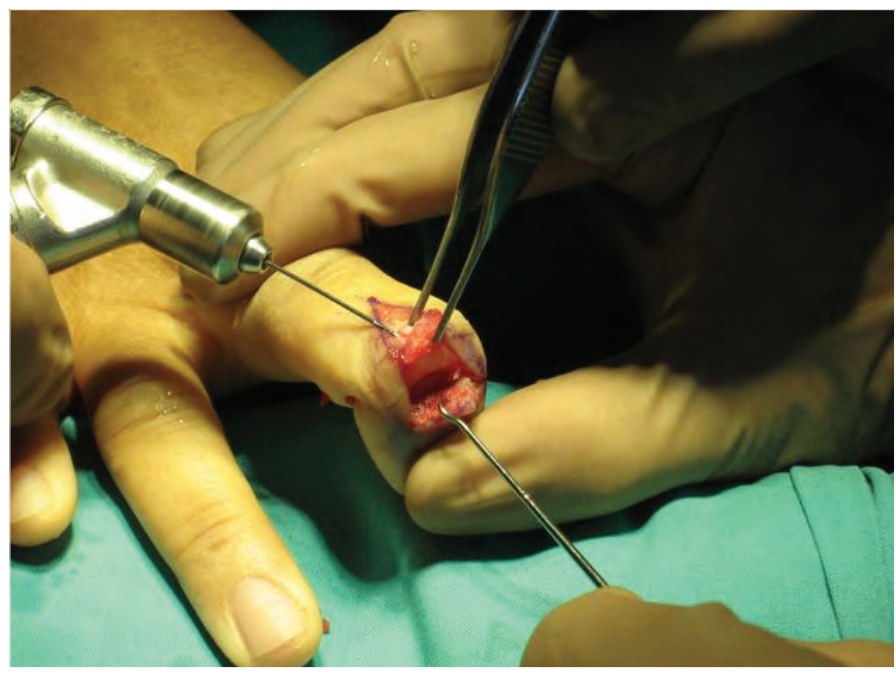

Figure 2. Two holes are drilled parallel starting from the raw fracture surface and exiting on the dorsal base at the insertion of the extensor tendon.

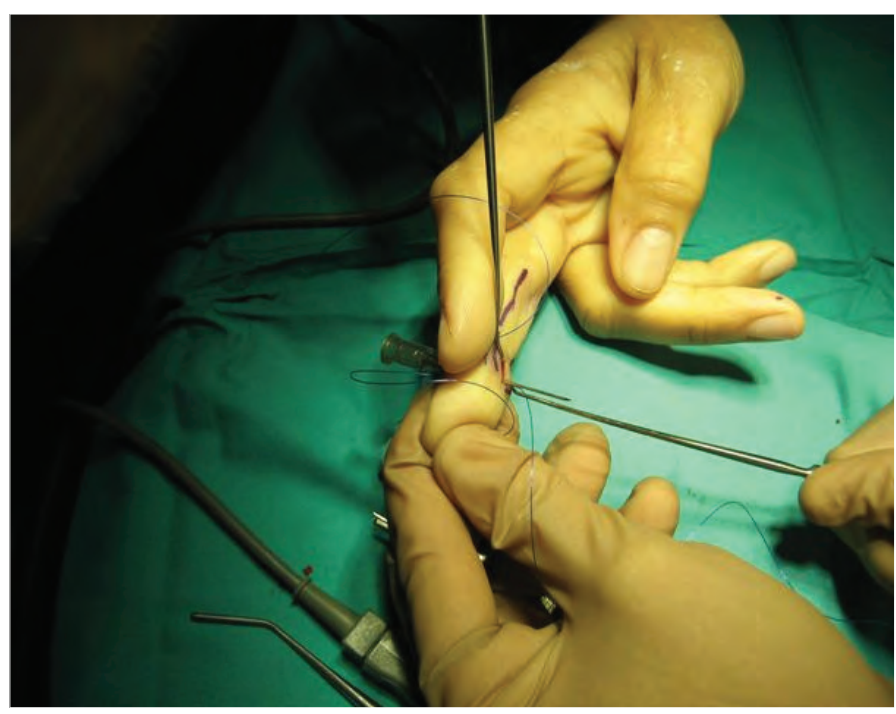

Figure 3. The two needles are passed through the volar cortex and delivered into a second separate longitudinal volar incision at the base of the terminal pulp. It is important to get the dissection all the way down to the flexor insertion at the level of the periosteum. It is mandatory that no soft tissue gets trapped by the suture material. 


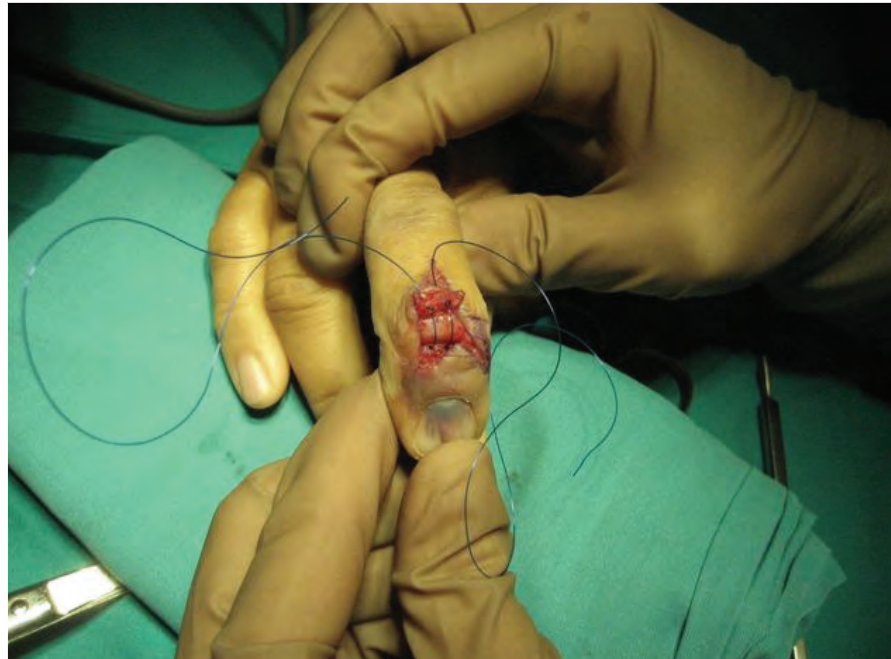

Figure 4. Using two separate needles through the dorsal fracture fragment, the same two ends of the prolene are now passed from volar to dorsal through the fracture fragment.

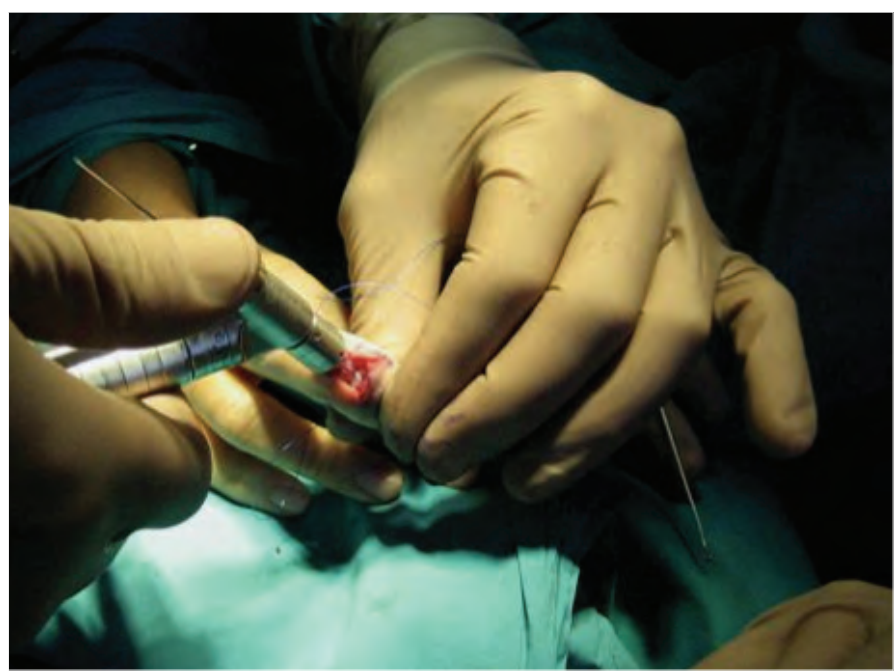

Figure 5. K-wire through the fracture site.

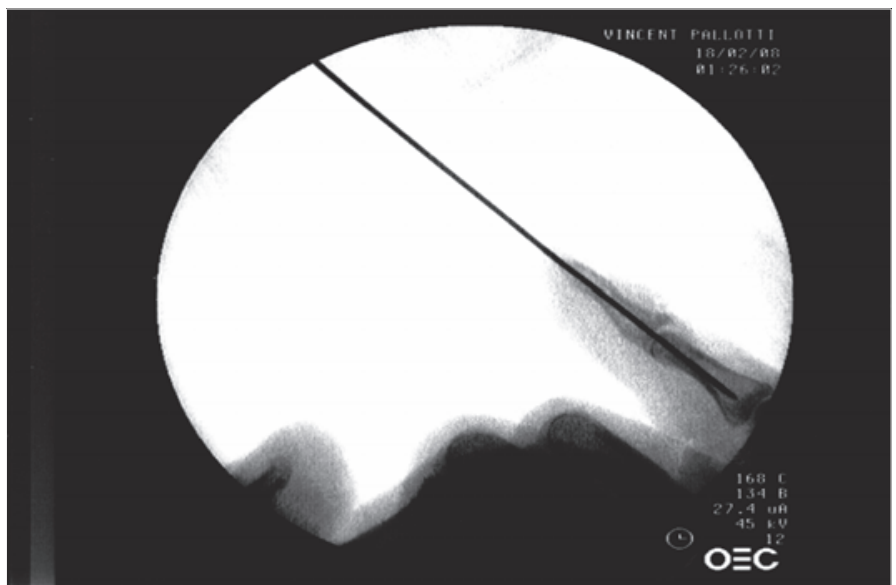

Figure 6. An image intensifier is used to confirm perfect reduction.

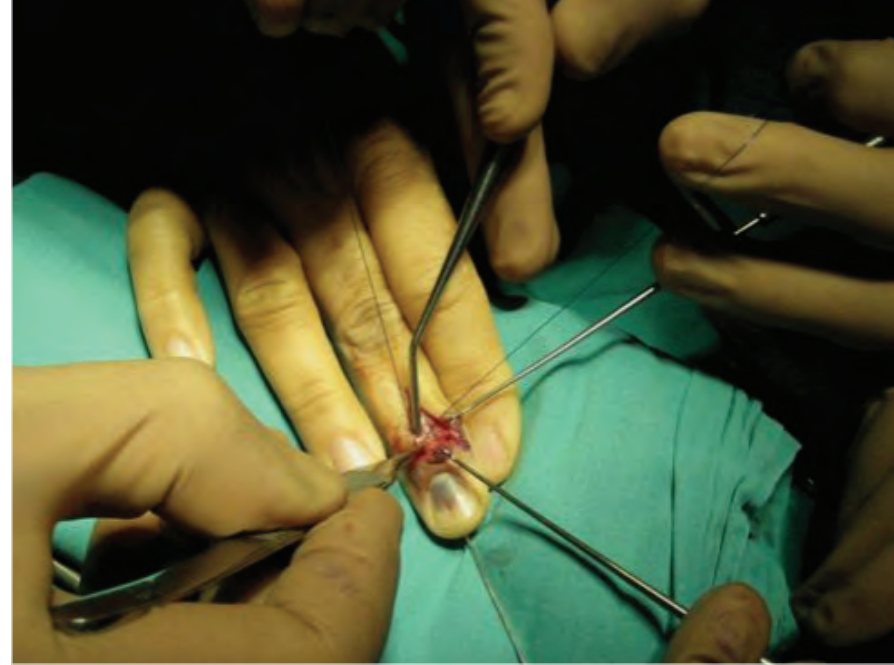

Figure 7. Once the reduction is confirmed the K-wire is driven across the fragment and the suture is carefully tied.
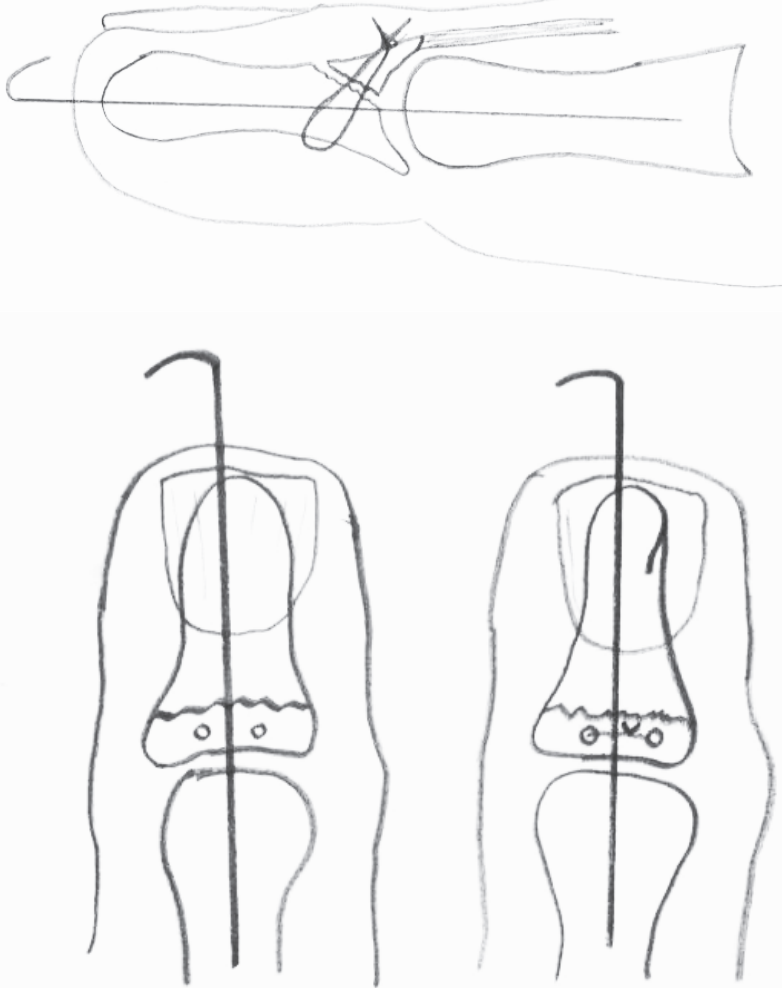

Figure 8. An illustration of the final result.

The next stage involves reducing the joint and passing a $\mathrm{K}$-wire in a pro-grade and then retrograde direction. It is desirable to try and pass the K-wire through the intact volar cartilage. Failing this, one runs the risk of blocking the reduction of the fracture due to the K-wire transgressing the fracture site. If this is not possible then it is necessary to pass the K-wire through the fracture site and withdraw it so that there is no K-wire evident when the fracture is reduced (Figure 5).

On reducing the fracture, one can then pass the K-wire carefully across the DIPJ in a retrograde manner. Our choice is for a .035 K-wire (mm). Using two separate needles through the dorsal fracture 
fragment, the same two ends of the prolene are now passed from volar to dorsal through the fracture fragment (Figure 4). It is now time to reduce the fracture. The fracture is reduced and held. An image intensifier is used to confirm perfect reduction (Figure 6). Once the reduction is confirmed the $\mathrm{K}$-wire is driven across the fragment and the suture is carefully tied (Figure 7). The final result of this is illustrated in Figure 8.

Haemostasis is achieved and the wound is closed with interrupted 5-0 nylon.

Due to the fact that there is a K-wire across the joint, no external splint is necessary. A bulky dressing is applied, with removal of sutures at ten days. The wire is normally kept in position for a minimum of four weeks and then the patient is carefully mobilised with a removable thermoplastic splint. Active motion only is allowed for the first two weeks, with gentle passive motion starting at six weeks.

\section{Results}

All patients were reviewed at three months post-surgery by the senior author.

Nine of the operated patients had Crawford classification graded as excellent. Two patients were classified as good and one (20-degree extension lag) patient as fair. Eleven out of the 12 patients all had complete bone union. There was one incident of non-union of the fracture site. This patient had a fair result. She did not want further surgery and the non-union remained stable. There were no incidents of fracture fragmentation.

With regard to soft tissue complications there were no sutures or wound dehisced. There was one superficial wound infection of the operated digit, which was managed conservatively with systemic antibiotics and this resolved clinically.

There were no nail abnormalities or injuries. There were two patients who accidentally caught the wires on stationary objects and they were pulled out but with no instability of the joint. There were no wound breakdowns and no swan-neck deformities. There were no dorsal bumps.

\section{Discussion}

Lange and Engber, in 1983, alerted the literature to the concept of the hyperextension mallet. ${ }^{1}$ It is the senior author's opinion that most mallet fractures that result in volar subluxation are the consequence of the hyperextension mallet. This was not specifically looked at in the study.

The indication for surgery in mallet fractures aside, the management can be extremely frustrating. Most surgeons would agree that trying to insert any form of hardware is frustrated by the comminution of these fragments.

This substantially complicates the options available. Surgeons have utilised various techniques including internal fixation, ,5,6,8,9,11-14,18-24 external fixation ${ }^{25}$ and various suture techniques. ${ }^{6,13,26}$ Even suture anchors have been used. The technique that comes closest to ours is that is used by Ulusoy et al. ${ }^{13}$ Bauze and Bain have also used a technique of a suture; their suture is also trans-osseous but goes around the extensor insertion to act more like a tension band concept. ${ }^{6}$

We utilise a full interosseous suture technique with the ability to get a perfect reduction and a stable fixation. The operation is simple, reliable and replicable. In our hands, this remains our technique of choice.

\section{Compliance with ethics guidelines}

Ethics committee approval for this retrospective study was obtained. Informed consent was obtained from all patients and clinical notes and radiological material were reviewed.

\section{References}

1. Lange $\mathrm{RH}$, Engber WD. Hyperextension mallet finger. Orthopedics. 1983;6(11):1426-31.

2. Wehbe MA, Schneider LH. Mallet fractures. J Bone Joint Surg Am 1984;66(5):658-69.

3. Schneider LH. Fractures of the distal interphalangeal joint. Hand Clin. 1994;10(2):277-85.

4. Damron TA, Engber WD. Surgical treatment of mallet finger fractures by tension band technique. Clin Orthop Relat Res. 1994(300):133-40.

5. Darder-Prats A, Fernandez-Garcia E, Fernandez-Gabarda R, DarderGarcia A. Treatment of mallet finger fractures by the extension-block K-wire technique. J Hand Surg Br. 1998;23(6):802-805.

6. Bauze A, Bain GI. Internal suture for mallet finger fracture. J Hand Surg Br. 1999;24(6):688-92.

7. Stark HH, Boyes JH, Wilson JN. Mallet finger. J Bone Joint Surg Am. 1962;44-a:1061-68.

8. Abouna JM, Brown $\mathrm{H}$. The treatment of mallet finger. The results in a series of 148 consecutive cases and a review of the literature. $\mathrm{Br} J$ Surg. 1968;55(9):653-67.

9. Jupiter JB, Sheppard JE. Tension wire fixation of avulsion fractures in the hand. Clin Orthop Relat Res. 1987(214):113-20.

10. Badia A, Riano F. A simple fixation method for unstable bony mallet finger. J Hand Surg Am. 2004;29(6):1051-55.

11. Fritz D, Lutz M, Arora R, Gabl M, Wambacher M, Pechlaner S. Delayed single Kirschner wire compression technique for mallet fracture. J Hand Surg Br. 2005;30(2):180-84.

12. Rocchi L, Genitiempo M, Fanfani F. Percutaneous fixation of mallet fractures by the 'umbrella handle' technique. J Hand Surg Br. 2006;31(4):407-12.

13. Ulusoy MG, Karalezli N, Kocer U, Uysal A, Karaaslan O, Kankaya Y, et al. Pull-in suture technique for the treatment of mallet finger. Plast Reconstr Surg. 2006;118(3):696-702.

14. Nelis R, Wouters DB. Is the use of biodegradable devices in the operative treatment of avulsion fractures of fingers, the so-called mallet finger advantageous? A feasibility study with meniscus arrows. Open Orthop J. 2008;2:151-54.

15. Lee SK, Kim KJ, Yang DS, Moon KH, Choy WS. Modified extensionblock K-wire fixation technique for the treatment of bony mallet finger. Orthopedics. 2010;33(10):728.

16. Zhang X, Meng H, Shao X, Wen S, Zhu H, Mi X. Pull-out wire fixation for acute mallet finger fractures with $\mathrm{k}$-wire stabilization of the distal interphalangeal joint. J Hand Surg Am. 2010;35(11):1864-69.

17. Miura T. Extension block pinning using a small external fixator for mallet finger fractures. J Hand Surg Am. 2013:38(12):2348-52.

18. Aarts FL, Derks R, Wouters DB. The Meniscus Arrow(R) as a fixation device for the treatment of mallet fractures: results of 50 cases. Hand (N Y). 2014;9(4):499-503.

19. Mazurek MT, Hofmeister EP, Shin AY, Bishop AT. Extension-block pinning for treatment of displaced mallet fractures. Am J Orthop (Belle Mead NJ). 2002;31(11):652-54

20. Hofmeister EP, Mazurek MT, Shin AY, Bishop AT. Extension block pinning for large mallet fractures. J Hand Surg Am. 2003;28(3):453-59.

21. Pegoli L, Toh S, Arai K, Fukuda A, Nishikawa S, Vallejo IG. The Ishiguro extension block technique for the treatment of mallet finger fracture: indications and clinical results. J Hand Surg Br. 2003;28(1):15-17.

22. Kronlage SC, Faust D. Open reduction and screw fixation of mallet fractures. J Hand Surg Br. 2004;29(2):135-38.

23. Damron TA, Engber WD, Lange RH, McCabe R, Damron LA, UIm M, et al. Biomechanical analysis of mallet finger fracture fixation techniques. J Hand Surg Am. 1993;18(4):600-607; discussion 8.

24. Theivendran K, Mahon A, Rajaratnam V. A novel hook plate fixation technique for the treatment of mallet fractures. Ann Plast Surg. 2007;58(1):112-15.

25. Kaleli T, Ozturk C, Ersozlu S. External fixation for surgical treatment of a mallet finger. J Hand Surg Br. 2003;28(3):228-30.

26. Cheon SJ, Lim JM, Cha SH. Treatment of bony mallet finger using a modified pull-out wire suture technique. J Hand Surg Eur Vol. 2011;36(3):247-49. 